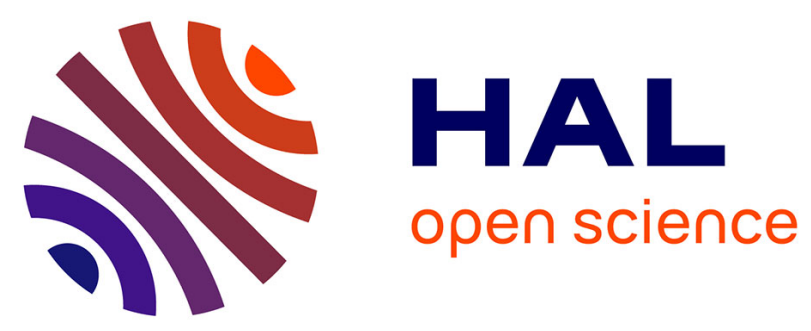

\title{
Quantification of palm oil bioactive compounds by ultra-high-performance supercritical fluid chromatography and chemometrics
}

Luciana Souza Guedes, Cesar Costapinto Santana, Douglas Neil Rutledge, Licarion Pinto, Isabel Cristina Sales Fontes Jardim, Lucília Vilela Melo, Marisa Masumi Beppu, Márcia Cristina Breitkreitz

\section{To cite this version:}

Luciana Souza Guedes, Cesar Costapinto Santana, Douglas Neil Rutledge, Licarion Pinto, Isabel Cristina Sales Fontes Jardim, et al.. Quantification of palm oil bioactive compounds by ultra-highperformance supercritical fluid chromatography and chemometrics. Canadian Journal of Chemical Engineering, In press, 10.1002/cjce.23969 . hal-03040772

\section{HAL Id: hal-03040772}

\section{https://hal-agroparistech.archives-ouvertes.fr/hal-03040772}

Submitted on 4 Dec 2020

HAL is a multi-disciplinary open access archive for the deposit and dissemination of scientific research documents, whether they are published or not. The documents may come from teaching and research institutions in France or abroad, or from public or private research centers.
L'archive ouverte pluridisciplinaire HAL, est destinée au dépôt et à la diffusion de documents scientifiques de niveau recherche, publiés ou non, émanant des établissements d'enseignement et de recherche français ou étrangers, des laboratoires publics ou privés. 


\title{
Quantification of palm oil bioactive compounds by
}

\section{ultra-high-performance supercritical fluid chromatography and}

\section{chemometrics}

\author{
Luciana de Souza Guedes*1 | Cesar Costapinto Santana $^{1}$ | Douglas Neil Rutledge ${ }^{2,3}$ | Licarion \\ Pinto $^{4}$ | Isabel Cristina Sales Fontes Jardim ${ }^{5}$ | Lucília Vilela de Melo ${ }^{5}$ | Marisa Masumi \\ Beppu $^{1}$ | Márcia Cristina Breitkreitz ${ }^{5}$
}

\footnotetext{
${ }^{1}$ School of Chemical Engineering, University of Campinas, Campinas, SP, Brazil

${ }^{2}$ Université Paris-Saclay, INRAE, AgroParisTech, UMR SayFood, Paris, France

${ }^{3}$ National Wine and Grape Industry Centre, Charles Sturt University, Wagga Wagga, Australia

${ }^{4}$ Department of Fundamental Chemistry, Federal University of Pernambuco, Recife, PE, Brazil

${ }^{5}$ Institute of Chemistry, University of Campinas, Campinas, SP, Brazil
}

\section{Correspondence}

*Luciana de Souza Guedes, Av. Albert Einstein, 500 13083-852 Campinas SP Brazil.Email: 1souguedes@ hotmail.com

\begin{abstract}
Lycopene, beta-carotene, coenzyme Q10, and lutein are minor constituents of palm oil that are removed during biodiesel production to produce light-colored oils. With the aim to investigate the recovery of these valuable compounds, a separation method was developed to quantify carotenoids and coenzyme Q10 in palm oil by ultra-highperformance supercritical fluid chromatography. Due to the presence of interferents, different clean-up procedures were evaluated; however, these approaches were ineffective and the separation method was developed without this step. The chemometric method multivariate curve resolution-alternating least squares was employed to properly quantify lycopene, beta-carotene, and coenzyme Q10 in the presence of interferents. Lutein was sufficiently resolved to be quantified by a univariate method. Lycopene concentration was below the limit of quantification $3.12 \mu \mathrm{g} / \mathrm{mL}(3.12 \mathrm{x}$ $\left.10^{-3} \mathrm{~kg} / \mathrm{m}^{3}\right)$. Beta-carotene concentration was determined as being $183.48 \pm 1.66$ $\mu \mathrm{g} / \mathrm{mL}\left(183.48 \pm 1.66 \times 10^{-3} \mathrm{~kg} / \mathrm{m}^{3}\right)$. Coenzyme Q10 concentration was lower than the limit of detection $4.22 \mu \mathrm{g} / \mathrm{mL}\left(4.22 \times 10^{-3} \mathrm{~kg} / \mathrm{m}^{3}\right)$ and lutein concentration 9.24 $\mu \mathrm{g} / \mathrm{mL}\left(9.24 \times 10^{-3} \mathrm{~kg} / \mathrm{m}^{3}\right)$ was below the limit of quantification. The study showed the analytical challenges associated with the separation and quantification of minor constituents of a highly complex matrix such as palm oil and demonstrated that the recovery of beta-carotene could be economically viable due to its wide range of application in industry.
\end{abstract}

\section{KEYWORDS:}

carotenoids, coenzyme Q10, multivariate curve resolution-alternating least squares, palm oil, ultra-highperformance supercritical fluid chromatography 


\section{1 | INTRODUCTION}

Growing concerns over the impact of industry on the global environment has drawn considerable attention to a more sustainable use of the natural resources. Indisputably, major improvements in environmental performances have already been made by industrial companies, but they are still striving to develop more sustainable processes. In the Brazilian biofuel industry, palm oil is one of the feedstocks used in biodiesel production. During its production, carotenoids, coenzyme Q10, and other minor components are removed to produce light-colored oils and these potentially valuable compounds are lost. 1$]$ Recovery of carotenoids and coenzyme Q10 from palm oil before the refining process might be economically viable due to the high value of these bioactive compounds and their wide range of applications in industry.

Palm oil is mainly composed of triglycerides, a lesser amount of free fatty acids, and $1 \%$ of minor components, such as carotenoids (500-700 ppm), coenzyme Q10 (10-80 ppm), vitamin E (600-1000 ppm), sterols (250-620 ppm), squalene (200-600 ppm), and phospholipids (20-100 ppm). 2 There are more than 10 different types of carotenoids in palm oil. Beta-carotene is the major carotenoid and accounts for $50-56.02 \%$ of total carotenoid content. Lycopene is $1.0-1.3 \%$ while xanthophylls which include lutein, accounts for $2.2 \%$. 2.5

Carotenoids and coenzyme Q10 have been associated with a number of health benefits due to their antioxidant properties. $\underline{6} .8$ Studies have demonstrated that carotenoids help prevent cancer, diabetes, and cardiovascular diseases. ${ }^{9}[12]$ Many therapeutic benefits of coenzyme Q10 have also been reported, this bioactive compound has been implicated as a potential therapy for neurodegenerative disorders and cardiovascular diseases. ${ }^{13}$ Carotenoids and coenzyme Q10 have a wide range of applications in industry. These bioactive compounds are used in feed, food, supplement, pharmaceutical, and cosmetic products. According to the consulting company Grand View Research, Inc., the global market of carotenoids is expected to reach USD 1.74 billion by 2025 and the coenzyme Q10 market is expected to reach USD 1.36 billion by 2026. 16/17]

With the aim to increase resource-use efficiency and to favor a green chemistry process, a method for the separation of lycopene, beta-carotene, coenzyme Q10, and lutein from palm oil was developed by ultra-high-performance supercritical fluid chromatography (UHPSFC). This technique has become an alternative to high-performance liquid chromatography (HPLC) for the analysis of carotenoids because it enables separations that are difficult to achieve, such as separation of geometrical isomers. ${ }^{[18]} \mathrm{CO}_{2}$ is the most often-used mobile phase in UHPSFC because of its low cost, non-flammability, and availability with an adequate purity. Additionally, its critical properties are easily reached $\left(\mathrm{P}_{c}=7.38 \mathrm{MPa}, \mathrm{T}_{c}=304.13 \mathrm{~K}\right)$. 1920 The UHPSFC mobile phase is very flexible; the mobile phase polarity can be changed by the addition of organic modifiers thus allowing the simultaneous determination of compounds with different polarities. [19] 21]

The UHPSFC technique has been used to determine minor constituents of palm oil. Choo et al ${ }^{[22]}$ quantified total carotenoid content in palm oil by UHPSFC. Recovery and quantification of coenzyme Q10 was reported by Ng et al. ${ }^{[23]}$ To our knowledge no attempts have been made to separate and quantify lycopene, beta-carotene, coenzyme Q10, and lutein from palm oil by UHPSFC. The present study evaluated only isocratic elution because the separation method is intended to be scaled-up. The chemometric 
method, Multivariate Curve Resolution-Alternating Least Squares (MCR-ALS), was employed to properly quantify the target compounds due to the complexity of palm oil matrix and the presence of interferents.

\section{2 | EXPERIMENTAL}

\subsection{Chemicals and reagents}

Propane (99.5\%) and ultrapure $\mathrm{CO}_{2}(99.99 \%)$ were supplied by White Martins. HPLC-grade ethanol (EtOH) and methyl tert-butyl ether (MTBE) were acquired from Panreac. Tetrahydrofuran (THF) was bought from J.T.Baker. Analytical standard of lycopene, beta-carotene, and coenzyme Q10, and pharmaceutical secondary standard of lutein were acquired from SigmaAldrich. Palm oil was extracted at Universidade Tiradentes (Sergipe, Brazil).

\section{2 | Instrumentation}

All experiments were performed on a Waters Acquity UPC $^{2}$ system equipped with a binary solvent delivery pump used to supply the organic modifier and $\mathrm{CO}_{2}$, an autosampler that included partial loop volume injection system, two-position column oven compatible with $150 \mathrm{~mm}$ length columns, a single column heater compatible with $300 \mathrm{~mm}$ length columns, a photo-diode array detector (PDA) including a high pressure UV cell (400 bar) with a volume of $8 \mu \mathrm{L}$, and a dual-stage backpressure regulator

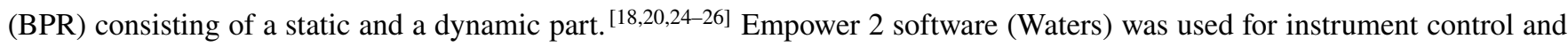
preliminary data analysis. Viridis $\mathrm{HSS} \mathrm{C}_{18}$ SB 3.0 x $150 \mathrm{~mm}$ column with particle size of $3.5 \mu \mathrm{m}$ was used.

\section{3 | Palm oil extraction}

Oil palm fresh fruit bunches (Dura variety) were provided by Empresa Baiana de Desenvolvimento Agrícola (EBDA). An extraction method previously developed employing supercritical fluid was used. These extraction conditions were selected because the largest quantity of carotenoids was recovered under these conditions. ${ }^{[27]}$ Fruits were separated from bunches, washed, and peeled manually. Palm fiber was dried in a circulating air oven (Nova Ética, 400/4N) at $60^{\circ} \mathrm{C}(333 \mathrm{~K})$ for 18 hours. After drying, palm fiber was ground in a knife mill, screened on a series of Tyler sieves and particle size between 8 to 24 mesh were selected. Samples were kept under refrigeration at $10^{\circ} \mathrm{C}(283 \mathrm{~K})$ prior to extraction.

Extraction was carried out in a semi-batch laboratory scale equipment. The equipment was comprised of a syringe pump (ISCO model 500D) for compressed fluid displacement, a cylindrical vessel $\left(0.25 \times 0.02\right.$ (i.d.) $\left.\mathrm{m}, 157.3 \times 10^{-6} \mathrm{~m}^{3}\right)$, a flow control valve, two thermostatic baths for fluid and extraction temperature control, and a pressure transducer (Huba Control, pressure transmitter type 691) to manage system pressure. ${ }^{[27]} 25 \mathrm{~g}(0.025 \mathrm{~kg})$ of palm fiber was loaded into the extraction vessel. Propane was pumped into the system followed by temperature and pressure setting at $40^{\circ} \mathrm{C}(313 \mathrm{~K})$ and $150 \mathrm{bar}(15 \mathrm{MPa})$. The system was kept at experimental condition for $40 \mathrm{~min}(2400 \mathrm{~s})$ and extraction was performed at $1 \mathrm{~mL} / \mathrm{min}\left(1.67 \times 10^{-8} \mathrm{~m}^{3} / \mathrm{s}\right)$ flow rate. 


\section{4 | Experimental design}

An experimental design was developed based on a previous study with the standard compounds. ${ }^{[28}$ The experimental domain was defined taking into account certain constraints, such as maximum pressure of the system, maximum temperature limit of the column, and carotenoids and coenzyme Q10 sensitivity to heat. Because the maximum allowed temperature for Viridis HSS $\mathrm{C}_{18} \mathrm{SB}$ column is $60^{\circ} \mathrm{C}(333 \mathrm{~K})$, a temperature range of $25-50^{\circ} \mathrm{C}(298-323 \mathrm{~K})$ was chosen. The ethanol percentage range (16-24, $\mathrm{v} / \mathrm{v}$ ) was selected based on preliminary experiments in which the lycopene peak was only identified when the ethanol percentage was higher than $15 \%$. The pressure range of 1500-2200 psi (10-15 MPa) was selected because this pressure interval is usually employed in UHPSFC separations and to enable the use of the ethanol range selected previously. ${ }^{28129}$

A central Composite Design (CCD), as used in the study with the standard compounds, was employed to design a series of experiments to determine the influence of the three operating parameters, pressure, temperature, and ethanol percentage on the two responses, retention factors $(k)$ and separation factors $\left(\alpha=k_{n} / k_{n-1}\right)$. ${ }^{[28]}$ The CCD experiments consisted of 8 factorial runs, 6 axial runs, and 5 replicates of the central point. ${ }^{[28[30]}$ The 19 runs were carried out in a randomized order to estimate the model coefficients and their corresponding errors. The range and levels of experimental variables investigated are presented in Table 1

TABLE 1 Coded and actual levels of the independent variables for UHPSFC experiments

\begin{tabular}{clccc}
\hline Symbol & Variables & \multicolumn{3}{c}{ Coded Levels } \\
\hline & & $\mathbf{- 1}$ & $\mathbf{0}$ & $\mathbf{+ 1}$ \\
\hline A & Pressure (MPa) & 10 & 13 & 15 \\
B & Temperature (K) & 298 & 310 & 323 \\
C & Ethanol percentage (\%) & 16 & 20 & 24 \\
\hline
\end{tabular}

Statistical analyzes were carried out by Design Expert software version 9.0 (Stat-Ease Inc.). The retention factors were transformed logarithmically to $\ln k$ and the polynomial models were obtained as follows:

$$
y=\beta_{0}+\sum_{j=1}^{k} \beta_{j} X_{j}+\sum \sum_{i<j} \beta_{i j} X_{i} X_{j}+\sum_{j=1}^{k} \beta_{j j} X_{j}^{2}
$$

where $\beta_{0}, \beta_{j}, \beta_{i j}$ and $\beta_{j j}$ are regression coefficients for intercept, linear, interaction and quadratic coefficients respectively and $\mathrm{X}_{i}$ and $\mathrm{X}_{j}$ are coded independent variables. 2831$]$ The regression models for each response were assessed by analysis of variance (ANOVA), diagnostics graphs (residuals and predicted values versus actual values) and the coefficient of determination $\left(\mathrm{R}^{2}\right) .{ }^{32[33]}$ The response surfaces were generated by holding one of the independent variables at constant value and changing the levels of the other two variables.

Chromatographic conditions employed in the experiment were: Viridis HSS $\mathrm{C}_{18}$ SB 3.0 x $150 \mathrm{~mm}$ column with particle size of $3.5 \mu \mathrm{m}$, sample manager temperature $17^{\circ} \mathrm{C}(290 \mathrm{~K})$, equilibration time between injections 4 minutes $(240 \mathrm{~s})$, flow rate $1.5 \mathrm{~mL} / \mathrm{min}\left(2.5 \times 10^{-8} \mathrm{~m}^{3} / \mathrm{s}\right)$, and injection volume $2 \mu \mathrm{L}\left(2 \times 10^{-9} \mathrm{~m}^{3}\right)$. All injections were carried out in triplicate and the average was calculated. After scanning in the 210-600 nm range, analytes were detected at $275 \mathrm{~nm}$ (coenzyme Q10) and 430 
$\mathrm{nm}$ (carotenoids). The palm oil sample (1250 mg, $\left.1250 \times 10^{-6} \mathrm{~kg}\right)$ was weighed and dissolved in $5 \mathrm{~mL}\left(5 \times 10^{-6} \mathrm{~m}^{3}\right)$ MTBE. Coenzyme Q10 (4.2 mg, $\left.4.2 \times 10^{-6} \mathrm{~kg}\right)$ was dissolved in $5 \mathrm{~mL}\left(5 \times 10^{-6} \mathrm{~m}^{3}\right)$ MTBE.

\subsection{Quantification of carotenoids and coenzyme Q10 in palm oil}

Quantification of carotenoid and coenzyme Q10 was carried out by the multiple standard addition method. Palm oil samples were spiked with each standard and the calibration curves were built in the concentration range: 5 to $50 \mu \mathrm{g} / \mathrm{mL}$ ( 5 to $50 \times 10^{-3}$ $\mathrm{kg} / \mathrm{m}^{3}$ ) for lycopene, 50 to $500 \mu \mathrm{g} / \mathrm{mL}$ (50 to $500 \times 10^{-3} \mathrm{~kg} / \mathrm{m}^{3}$ ) for beta-carotene, 8 to $100 \mu \mathrm{g} / \mathrm{mL}$ ( 8 to $100 \times 10^{-3} \mathrm{~kg} / \mathrm{m}^{3}$ ) for coenzyme Q10, and 8 to $60 \mu \mathrm{g} / \mathrm{mL}$ ( 8 to $60 \times 10^{-3} \mathrm{~kg} / \mathrm{m}^{3}$ ) for lutein. The palm oil sample $\left(1250 \mathrm{mg}, 1250 \times 10^{-6} \mathrm{~kg}\right.$ ) was weighed and dissolved in $5 \mathrm{~mL}\left(5 \times 10^{-6} \mathrm{~m}^{3}\right)$ MTBE. Lycopene, beta-carotene, and coenzyme Q10 were dissolved in MTBE, and lutein in THF.

Chromatographic conditions employed in the experiment were the same as those used in the experimental design, except for the mobile phase composition $\mathrm{CO}_{2}: \mathrm{EtOH}\left(82: 18\right.$, v/v), pressure $1600 \mathrm{psi}(11 \mathrm{MPa})$, and column temperature $40^{\circ} \mathrm{C}(313 \mathrm{~K})$. After scanning in the $210-600 \mathrm{~nm}$ range, analytes were detected at $275 \mathrm{~nm}$ (coenzyme Q10), $430 \mathrm{~nm}$ (lutein), $440 \mathrm{~nm}$ (beta-carotene), and $490 \mathrm{~nm}$ (lycopene).

\section{6 | Data analysis}

A variety of algorithms are available to process second-order data, such as parallel factor analysis (PARAFAC), ${ }^{[3]}$ alternating trilinear decomposition (ATLD), 35] generalized rank annihilation (GRAM), 36] direct trilinear decomposition (DTLD) 37 and bilinear least-squares combined with residual bilinearization (BLLS/RBL). ${ }^{[38}$ However, all these methods require that the sample-to-sample profiles remain constant in the retention time dimension or perform a realignment of the chromatograms before data processing. ${ }^{39140]}$ On the other hand, there are algorithms that offer an approach to handle retention time shifts ${ }^{39440}$, such as MCR-ALS, ${ }^{41]}$ PARAFAC2, ${ }^{[4]}$ a variant of PARAFAC, and the latent structured methods, unfolded partial least-squares (U-PLS) ${ }^{[4]}$ and multi-way PLS (N-PLS), ${ }^{44]}$ both combined with RBL.

MCR-ALS has been widely used to solve co-elution and retention time shifts, among other chemical problems encountered in chromatographic data. ${ }^{45,48]}$ The assumption of the MCR-ALS method is that the experimental data fulfills a bilinear model. The method decomposes the data into two matrices $\mathrm{C}$ and $S^{T}$ as in Equation 22:

$$
D=C S^{T}+E
$$

where $\mathrm{D}$ is the data matrix vertically augmented in the chromatographic mode, each individual chromatographic data matrix being set on top of the other, and $\mathrm{C}$ and $\mathrm{S}$ are matrices with the concentration and spectral profiles of the components in the mixtures, respectively. $\mathrm{E}$ is the matrix of the residuals after removing the contributions given by the components in $\mathrm{C}$ and $\mathrm{S}$. 48 Studies reported in the literature $49-51]$ have demonstrated that MCR-ALS enables a better modeling of the constituent properties 
and the quantification of analytes in complex samples than does PARAFAC2. The inadequate modeling of PARAFAC2 is attributed to the requirement of constant overlapping of any pair of elution time profiles across samples which is obeyed in a limited number of situations. 51

Palm oil chromatographic data was evaluated by MCR-ALS to quantify lycopene, beta-carotene, coenzyme Q10, and lutein in the presence of interferents. The MCR-ALS analysis was carried out using the toolbox MVC2 (multivariate calibration 2) written for MATLAB. ${ }^{[52]}$ Elution and spectral profiles of the target compounds were retrieved by solving Equation 2 iteratively by alternating least squares optimization. This calculation consists in initially augmenting the data in the chromatographic mode since peak shifts are present. It is important to perform the calculations on all data because the proportionality of the scores may change due to many factors like different interferents, estimated profiles and applied constraints. In this configuration the constituents are individually recovered by the differences in the spectral signal which is the non-augmented profiles. ${ }^{47]}$ To start the ALS optimization, the number of constituents that will be optimized is a required input that is generally estimated by single value decomposition. In contrast to methods like principal component analysis (PCA), the choice of the number of estimated components has an effect on the recovered profiles in MCR-ALS.

For the ALS optimization, it is necessary to have an initial profile of $\mathrm{C}$ or $\mathrm{S}$ that will then be iteratively optimized by adjustments based on a number of constraints. These adjustments are performed by a least squares procedure searching for the profiles that simultaneously fulfill the chosen constraints and minimize the residue matrix (E). Three criteria are used to stop the calculations, (1) small change between the new profiles and the ones of the previous iteration, generally this change is set to $0.1 \%$; (2) reaching the pre-defined maximum number of iterations; and (3) observing a sequence of 20 iterations that orient the profiles towards an increasing difference, i.e., a divergence. Profiles that diverge are not optimized, so the ideal is the first case where the profiles converged with a number of interactions lower than the pre-defined maximum. During the iterations some constraints are defined to reduce the number of possible results that lead to ambiguous profiles. [53]

For chromatographic data the following constraints are generally applied (1) unimodality of the chromatographic signals, where each constituent must provide a single peak; (2) non-negativity, where negative signals do not fulfill the physicochemical characteristics of the detector; and (3) normalization of the spectral profile to guarantee proportionality to the concentration profiles. Other constraints may be applied to specific cases. ${ }^{[45}$ With the optimized recovered profiles, it is possible to correlate the area under the peak with the known concentration of the respective analyte to build a pseudo calibration curve and predict the concentration in the oil sample. This calibration procedure is performed similar to a traditional chromatographic univariate calibration, differing only in the mathematical separation of each individual constituent, and so is called a pseudo-univariate calibration. ${ }^{[54]}$ It is possible to apply the unimodality constraint only to the analyte and set free the interferent profile, this may result in higher explained variation with a small number of profiles. In this way the recovered interferent profile consists of the sum of all of them, following the Beer-Lambert's law. ${ }^{[55]}$ The identity of the analyte may be confirmed by comparing the normalized spectrum of the recovered profile with the standard of each analyte. MCR-ALS results are validated with the quality of recovered concentration and spectral profiles. 


\section{3 | RESULTS AND DISCUSSION}

\section{1 | Clean-up procedures}

In a previous study, an analytical method for separation of carotenoids and coenzyme Q10 was developed employing the standard compounds. ${ }^{[28}$ The optimized operating conditions were then evaluated with palm oil. These preliminary results showed that there was a co-elution of some matrix components with the analytes. Furthermore, lower $\mathrm{S} / \mathrm{N}$ ratios and retention time shifts of the analytes in palm oil in relation to their standards were also observed which made it difficult to identify and quantify the target compounds. Due to these challenges, the addition of a clean-up procedure to physically reduce interference of matrix constituents followed by UHPSFC analysis was investigated.

Clean-up procedures employing Supelclean C18 and ENVI-8 solid-phase extraction cartridges, dispersive solid-phase extraction with primary secondary amine and graphitized carbon black sorbents, Amberlite XAD7HP resin, and saponification were tested to physically reduce interference from matrix components. The clean-up procedures showed similar qualitative chromatographic profiles, but with quantitative differences when compared with the sample dissolved in MTBE (the chromatograms are shown in Figure 1 in Supporting Information). It is interesting to note that the chromatogram without the clean-up procedure showed better resolution between peaks than those after the clean-up procedures. The results indicated that this approach was not suitable for removing interferents and the steps required to prepare the samples were not adequate for preparative purposes. In addition, the operating conditions optimized with standard compounds did not allow a proper identification and quantification of the analytes. Considering all these results, a separation method was developed without employing a clean-up step and the chemometric method, MCR-ALS, was used to identify and quantify the target compounds.

\section{2 | Experimental design}

The influence of pressure, temperature and ethanol percentage on retention and separation factors of carotenoids and coenzyme Q10 in palm oil was investigated by an experimental design. Regression models were built for lycopene, beta-carotene, and coenzyme Q10. Lutein was present at a low concentration and its peak was only visible after addition of the standard compound.

\subsection{1 | Retention factor}

The models for retention factors showed that retention strongly depends on the operating conditions. Ethanol percentage was the parameter that most affected the retention factors followed by pressure, while temperature had a weaker influence on the retention as shown in Figure 1. For all models, the $\mathrm{AB}$ and $\mathrm{AC}$ terms were significant $(\mathrm{P}<0.05)$ whereas the $\mathrm{BC}$ term was only significant for beta-carotene model. The second-order terms were not significant $(\mathrm{P}>0.05)$ except the $\mathrm{C}^{2}$ term for beta-carotene model.

The regression models were assessed by ANOVA and the results are reported in Table 2 The fit of the models was evaluated by the coefficient of determination $\left(\mathrm{R}^{2}\right)$ and the values were $0.9802,0.9898$ and 0.9819 for lycopene, beta-carotene and coenzyme Q10 models, respectively. The residual graphs were also evaluated and presented a homoscedastic, random pattern, as expected. 


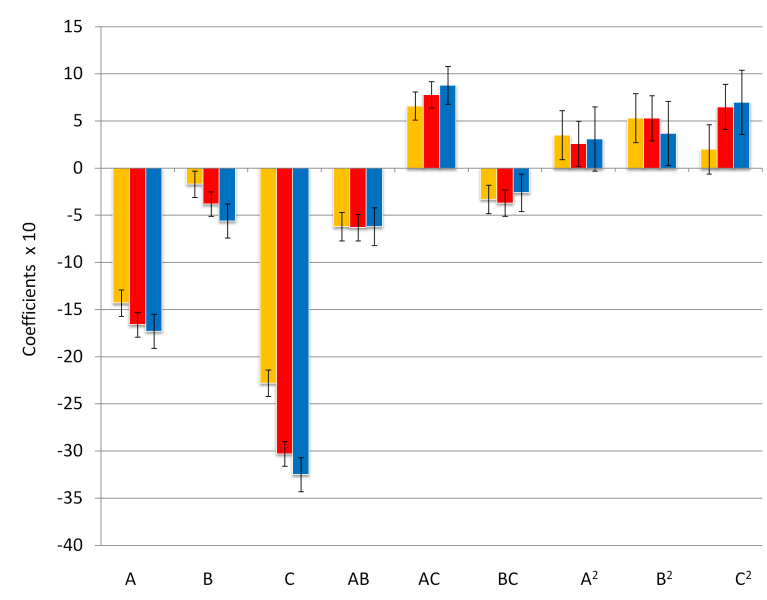

FIGURE 1 Coefficients of the model for the retention factors of lycopene (orange), beta-carotene (red) and coenzyme Q10 (blue). The error bars represent the $95 \%$ confidence interval of the coefficients. A is pressure, $\mathrm{B}$ is temperature and $\mathrm{C}$ is ethanol percentage; $\mathrm{AB}, \mathrm{AC}$ and $\mathrm{BC}$ are interaction terms; $\mathrm{A}^{2}, \mathrm{~B}^{2}$ and $\mathrm{C}^{2}$ are second-order terms.

The graphs of predicted vs actual responses indicated an excellent prediction capability of the proposed models. The final regression model equations for the retention factors obtained in terms of coded factors were:

$$
\begin{aligned}
\ln _{\text {lycopene }} & =11.78-1.43 A-0.17 B-2.28 C-0.62 A B+0.66 A C \\
& -0.33 B C+0.35 A^{2}+0.53 B^{2}+0.20 C^{2} \\
\operatorname{lnk}_{\text {beta-carotene }} & =14.07-1.66 A-0.38 B-3.03 C-0.63 A B+0.78 A C \\
& -0.37 B C+0.26 A^{2}+0.53 B^{2}+0.65 C^{2} \\
\ln k_{\text {coenzymeQ } 10}= & 15.67-1.73 A-0.56 B-3.25 C-0.62 A B+0.88 A C \\
& -0.26 B C+0.31 A^{2}+0.37 B^{2}+0.70 C^{2}
\end{aligned}
$$

In order to visualize the effect of the independent variables on the retention factors, response surface plots were generated by varying pressure and ethanol percentage within the experimental range while holding temperature at a constant value (Figure 2. Low values for the retention factors were achieved at high ethanol percentage, high pressure, and high temperature. It is interesting to note that at high ethanol percentage, an increase in pressure had a slight effect on the retention factors while substantial changes in the retention factors were observed at low ethanol percentage. This is represented in the model by the significant coefficient AC and it can be explained based on the density of the fluid. At lower amounts of ethanol the fluid is more compressible, therefore the pressure has a greater effect. Temperature had a minor effect on the retention factors as illustrated by the response surface plots at $25^{\circ} \mathrm{C}(298 \mathrm{~K})$ and $50^{\circ} \mathrm{C}(323 \mathrm{~K})$. 
TABLE 2 ANOVA for the quadratic model for the retention factors of lycopene, beta-carotene and coenzyme Q10.

\begin{tabular}{|c|c|c|c|c|c|}
\hline Source & $\begin{array}{l}\text { Sums of } \\
\text { squares }\end{array}$ & DF & Mean square & F value & Prob $>$ F \\
\hline \multicolumn{6}{|c|}{ Lycopene } \\
\hline Model & 83.97 & 9 & 9.33 & 49.60 & $<0.0001$ \\
\hline $\mathbf{A}-\mathbf{P}$ & 20.53 & 1 & 20.53 & 109.14 & $<0.0001$ \\
\hline B-T & 0.28 & 1 & 0.28 & 1.50 & 0.2518 \\
\hline C-C ${ }_{E}$ & 51.77 & 1 & 51.77 & 275.19 & $<0.0001$ \\
\hline $\mathbf{A B}$ & 3.05 & 1 & 3.05 & 16.23 & 0.0030 \\
\hline $\mathbf{A C}$ & 3.47 & 1 & 3.47 & 18.46 & 0.0020 \\
\hline BC & 0.85 & 1 & 0.85 & 4.52 & 0.0625 \\
\hline$A^{2}$ & 0.33 & 1 & 0.33 & 1.73 & 0.2206 \\
\hline $\mathbf{B}^{2}$ & 0.76 & 1 & 0.76 & 4.06 & 0.0748 \\
\hline $\mathrm{C}^{2}$ & 0.11 & 1 & 0.11 & 0.56 & 0.4722 \\
\hline \multicolumn{6}{|c|}{ Beta-carotene } \\
\hline Model & 136.88 & 9 & 15.21 & 96.89 & $<0.0001$ \\
\hline $\mathbf{A}-\mathbf{P}$ & 27.50 & 1 & 27.50 & 175.21 & $<0.0001$ \\
\hline B-T & 1.47 & 1 & 1.47 & 9.34 & 0.0137 \\
\hline C-C ${ }_{E}$ & 91.53 & 1 & 91.53 & 583.11 & $<0.0001$ \\
\hline $\mathbf{A B}$ & 3.16 & 1 & 3.16 & 20.16 & 0.0015 \\
\hline $\mathrm{AC}$ & 4.92 & 1 & 4.92 & 31.37 & 0.0003 \\
\hline BC & 1.08 & 1 & 1.08 & 6.87 & 0.0277 \\
\hline$A^{2}$ & 0.18 & 1 & 0.18 & 1.14 & 0.3141 \\
\hline $\mathbf{B}^{2}$ & 0.78 & 1 & 0.78 & 4.94 & 0.0534 \\
\hline $\mathbf{C}^{2}$ & 1.16 & 1 & 1.16 & 7.38 & 0.0237 \\
\hline \multicolumn{6}{|c|}{ Coenzyme Q10 } \\
\hline Model & 155.30 & 9 & 17.26 & 54.16 & $<0.0001$ \\
\hline A-P & 30.01 & 1 & 30.01 & 94.18 & $<0.0001$ \\
\hline B-T & 3.15 & 1 & 3.15 & 9.89 & 0.0118 \\
\hline $\mathbf{C}-\mathbf{C}_{E}$ & 105.66 & 1 & 105.66 & 331.63 & $<0.0001$ \\
\hline $\mathbf{A B}$ & 3.04 & 1 & 3.04 & 9.55 & 0.0129 \\
\hline $\mathbf{A C}$ & 6.23 & 1 & 6.23 & 19.56 & 0.0017 \\
\hline BC & 0.55 & 1 & 0.55 & 1.74 & 0.2203 \\
\hline$A^{2}$ & 0.26 & 1 & 0.26 & 0.82 & 0.3890 \\
\hline $\mathbf{B}^{2}$ & 0.38 & 1 & 0.38 & 1.20 & 0.3009 \\
\hline $\mathbf{C}^{2}$ & 1.32 & 1 & 1.32 & 4.16 & 0.0719 \\
\hline
\end{tabular}

\subsection{2 | Separation factor}

In contrast to the retention factor models, the polynomial regression models for the separation factors were not in good agreement with experimental results. Carotenoids and coenzyme Q10 eluted in close proximity and minor changes in the operating conditions resulted in beta-carotene and coenzyme Q10 co-elution. Thus, this pair of peaks was considered critical in the method development. The lycopene peak was identified when intermediate pressure and ethanol percentage were used. Additionally, it was observed that at high temperature, the peak was distorted. From these findings, the 19 chromatograms from the experimental design were visually inspected and compared to one another in order to identify the operating conditions that could lead to an adequate separation between beta-carotene and coenzyme Q10 and a proper identification of the lycopene peak. Based on this 

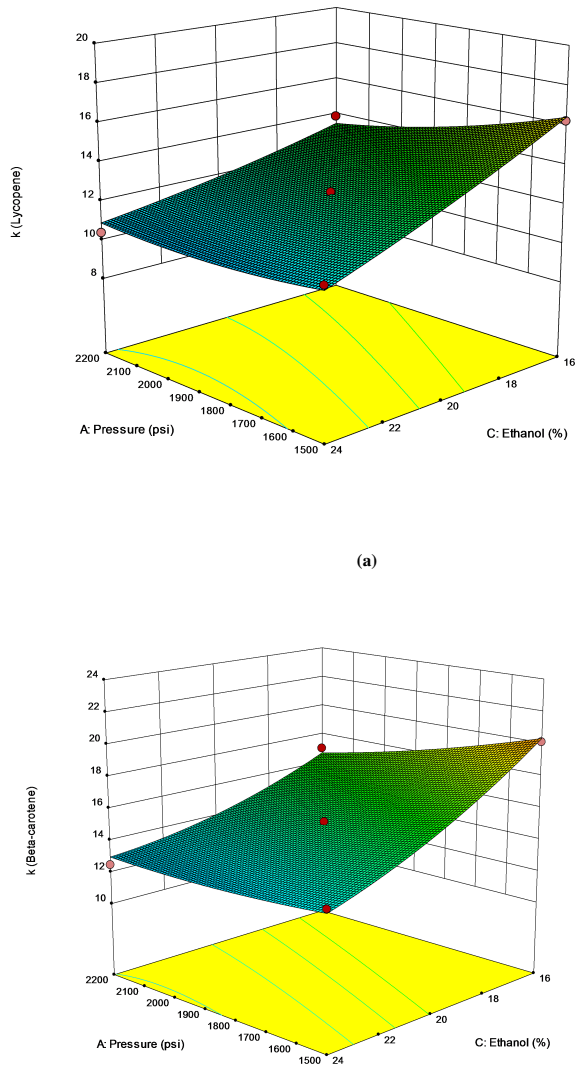

(c)

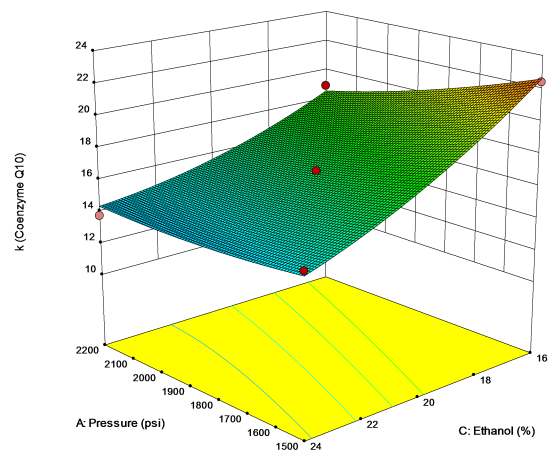

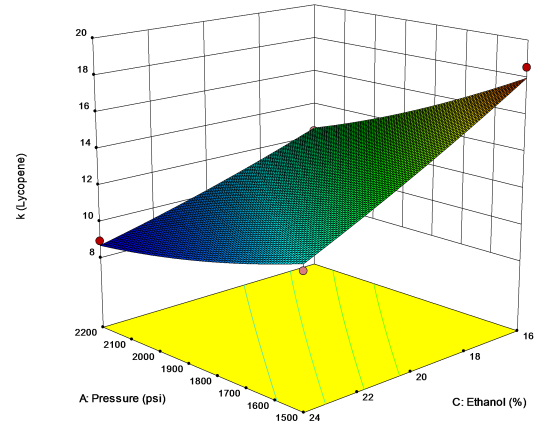

(b)

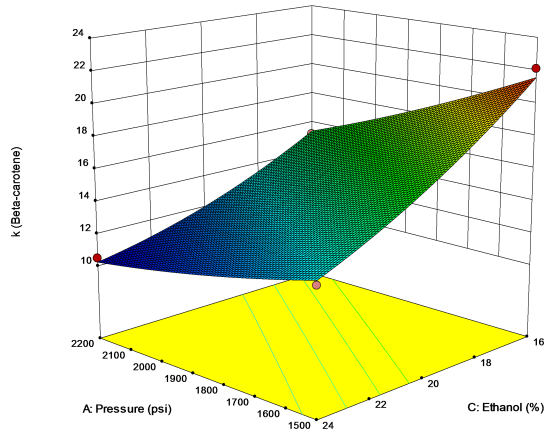

(d)

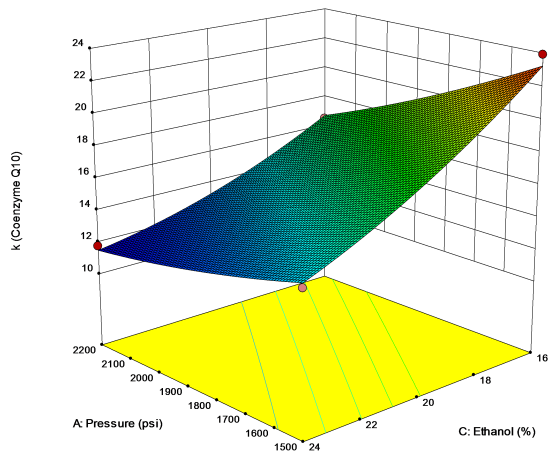

(f)

FIGURE 2 Response surface plots of the retention factor of lycopene (a/b), beta-carotene (c/d), and coenzyme Q10 (e/f) as a function of ethanol percentage and pressure at $25^{\circ} \mathrm{C}(298 \mathrm{~K})$ on the left and $50^{\circ} \mathrm{C}(323 \mathrm{~K})$ on the right.

evaluation two additional experiments were carried out. The experiments were performed with palm oil samples spiked with coenzyme Q10 to evaluate the separation. One experiment was carried out at a pressure of $1850 \mathrm{psi}$ (13 MPa), column temperature $25^{\circ} \mathrm{C}(298 \mathrm{~K})$ and $18 \%$ ethanol and the other one was conducted at a pressure of $1600 \mathrm{psi}(11 \mathrm{MPa})$, column temperature $40^{\circ} \mathrm{C}(313 \mathrm{~K})$ and $18 \%$ ethanol. Chromatograms obtained under these operating conditions are shown in Figure 3 . Co-elution 
was observed between beta-carotene and coenzyme Q10 peaks in the first conditions (Figure 3a), while baseline resolution was achieved in the second (Figure 3b. Considering these results, the operating conditions selected for quantification of carotenoids and coenzyme Q10 in palm oil were: pressure $1600 \mathrm{psi}(11 \mathrm{MPa})$, column temperature $40^{\circ} \mathrm{C}(313 \mathrm{~K})$, and $18 \%$ of ethanol.

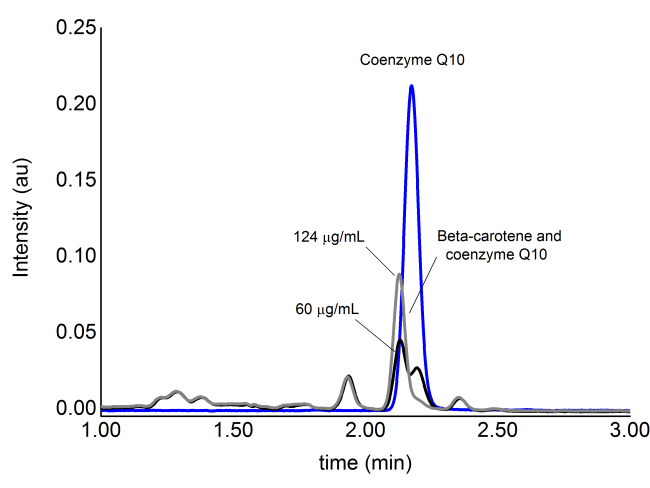

(a)

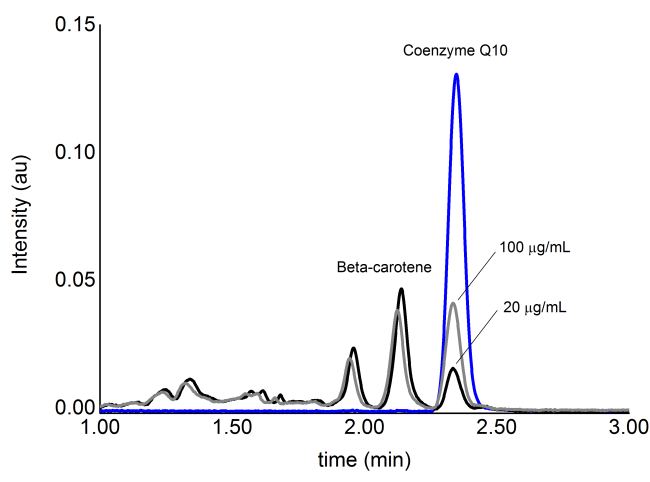

(b)

FIGURE 3 Chromatograms of palm oil samples spiked with coenzyme Q10 at $275 \mathrm{~nm}$. Chromatographic conditions: (a) pressure $1850 \mathrm{psi}(13 \mathrm{MPa})$, column temperature $25^{\circ} \mathrm{C}(298 \mathrm{~K})$ and $18 \%$ of ethanol, and (b) $1600 \mathrm{psi}$ (11 MPa), column temperature $40^{\circ} \mathrm{C}(313 \mathrm{~K})$ and $18 \%$ of ethanol.

\subsection{Quantification of carotenoids and coenzyme Q10 in palm oil}

Quantification of carotenoids and coenzyme Q10 was carried out by the UHPSFC technique. Calibration curves were built separately due to differences in analyte solubility. Carotenoid solubility depends on the presence of different functional groups. Carotenes, compounds such as lycopene and beta-carotene containing only carbon and hydrogen in their backbone are soluble in non-polar solvents such as hexane, ethyl acetate and MTBE, while xanthophylls such as lutein, also contain oxygen and are soluble in polar solvents like ethanol and acetone. ${ }^{[56]}$ Chromatograms of palm oil samples spiked with lycopene, beta-carotene, coenzyme Q10, and lutein are shown in Figure 4

\section{4 | MCR-ALS analysis}

The broad range of constituents in the palm oil matrix, and the difficulty in separating carotenoid geometrical isomers represented an additional degree of complexity for the separation and quantification of lycopene, beta-carotene, coenzyme Q10 and lutein. Moreover, a desired separation could not be achieved despite the clean-up procedures and changes on the experimental conditions. For samples of complex composition such as palm oil, the coupling of chromatographic analysis with chemometric tools is an alternative to increase the selectivity by mathematical means. ${ }^{39440}$ Most carotenoids have similar UV-Vis spectra ${ }^{57}$ and each compound can have more than one isomer. During the MCR-ALS calculations, a model with more components was evaluated in an attempt to identify the interferents, however, the carotenoid and coenzyme Q10 profiles were more accurately 


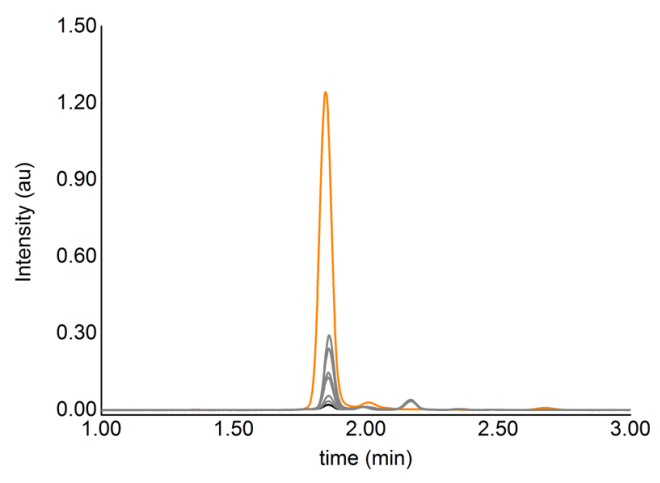

(a)

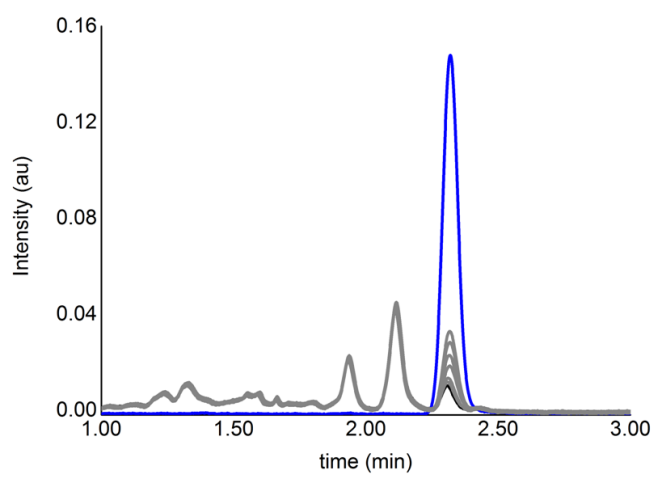

(c)

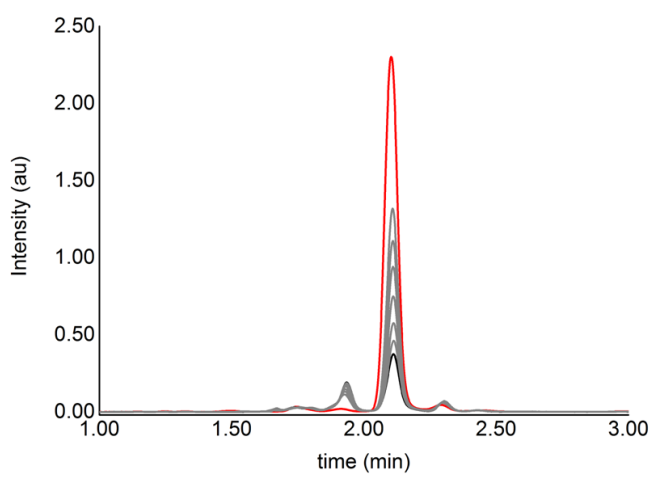

(b)

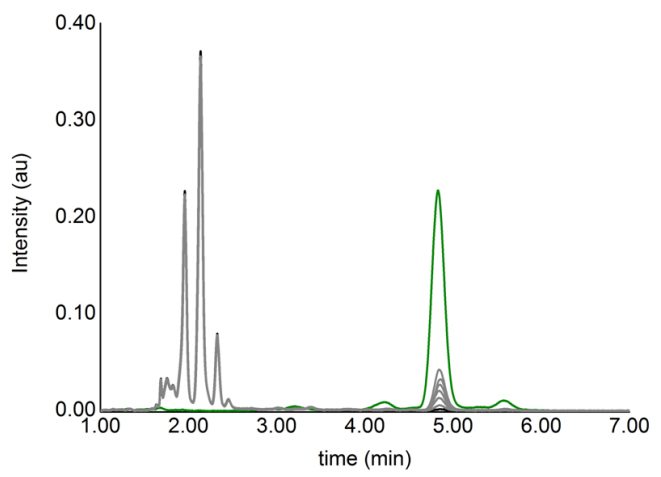

(d)

FIGURE 4 Chromatograms of palm oil samples spiked with (a) lycopene, (b) beta-carotene, (c) coenzyme Q10, and (d) lutein. Chromatogram colors refer to lycopene (orange), beta-carotene (red), coenzyme Q10 (blue), lutein (green), palm oil samples (black), and fortified palm oil samples (grey).

resolved with fewer components (referring to the bioactive compounds of interest) in the model. This is because the standard addition increased the intensity of the analyte signals and enabled the algorithm to identify the source of variability which resulted in a better recovery of the profiles.

As the main goal of this work was to show how it is possible to quantify the bioactive compounds of interest in the presence of unidentified compounds of the complex matrix of palm oil, it is only necessary to mathematically separate them from the interferents, without the need to separate all the individual unknown compounds among themselves. It was therefore decided to recover them as one or more profiles collectively called "unknown compounds". Identification of other carotenoids by comparing the experimental UV-Vis spectra with those reported in the literature was not effective because UV-Vis spectra are usually obtained in organic solvents ${ }^{[58]}$ and not in carbon dioxide or carbon dioxide/organic modifier mixture. The UV-Vis spectral features, wavelength of maximum absorption $\left(\lambda_{\max }\right)$, spectral shape, and intensity of absorption, provide valuable information for structural characterization and quantitative analysis. ${ }^{[58]}$ However, the first two features are solvent dependent. ${ }^{[58]}$ Moreover, in supercritical fluid, the $\lambda_{\max }$ is dependent on the percentage of the organic modifier as demonstrated by the study done by $\mathrm{Ng}$ 
et al. ${ }^{3]}$ Shift of the $\lambda_{\max }$ to longer wavelengths was observed as the percentage of the organic modifier increased. Due to these limitations, identification of other carotenoids in the palm oil sample was not attempted. A thorough identification of the other bioactive compounds and isomers would require a mass detector and/or standards for all the other compounds and is beyond the scope of this work. $[59-62]$

Elution and spectral profiles retrieved by MCR-ALS are illustrated in Figure 5 As can be seen in Figures $5 \mathrm{a}$ and $5 \mathrm{~b}$. lycopene co-eluted with two unknown compounds. In a similar fashion, beta-carotene co-eluted with an unknown compound. It is interesting to note that the unknown compound has a UV/Vis spectrum characteristic of a carotenoid with respect to its fine structure (Figures 5c and 5d). Coenzyme Q10 also co-eluted with an unknown compound (Figures 5e and 5f]. The results suggest that this unknown compound may be a lutein isomer. The lutein peak was only observed in spiked palm oil samples (Figures $5 \mathrm{~g}]$ and 5h. However, a comparison between the spectra of unknown compounds 1 and 2, and the lutein standard showed great similarity in their fine structure (Figures $6 \mathrm{a}$ and $6 \mathrm{~b}$. The difference between the spectrum of the unknown compound 2 and the others is the position of the cis peak around $330 \mathrm{~nm}$. Lutein geometrical isomers, 13-Z and 13'-Z, 9-Z and 9'-Z, have been reported in the literature. ${ }^{[63]}$ Additionally, the intensity of the cis peak gives insight into the position of the cis double bond; its intensity increases as the position of the double bond approaches the center of the molecule. [57]

Liquid chromatography and UV-Visible spectroscopy are the analytical techniques of choice for determining carotenoids in different matrices. ${ }^{[64]}$ Most studies with palm oil report total carotenoid content. ${ }^{[465.72]}$ The concentrations of lycopene, betacarotene, and coenzyme Q10 were determined by the MCR-ALS method because of the co-elution of the target compounds with palm oil matrix constituents, whereas the lutein concentration was determined by a univariate method (Table 3). Pseudounivariate calibration curves for lycopene, beta-carotene, and coenzyme Q10 and the univariate calibration curve for lutein are shown in Figure 7

TABLE 3 Linear regression outputs for carotenoids and coenzyme Q10

\begin{tabular}{lcccc}
\hline Compound & $\begin{array}{c}\text { Concentration } \\
(\mu \mathbf{g} / \mathbf{m L})\end{array}$ & $\begin{array}{c}\text { Linear range } \\
(\mu \mathbf{g} / \mathbf{m L})\end{array}$ & LOD & LOQ \\
\hline Lycopene $^{b}$ & $<\mathrm{LOQ}$ & $5-50$ & 1.03 & 3.12 \\
Beta-carotene $^{b}$ & $183.48( \pm 1.66)$ & $50-500$ & 8.45 & 25.79 \\
Coenzyme Q10 $^{b}$ & $<\mathrm{LOD}$ & $8-100$ & 4.22 & 12.72 \\
Lutein $^{c}$ & $<\mathrm{LOQ}$ & $8-60$ & 2.77 & 9.24 \\
\hline
\end{tabular}

a Mean value of three replicates $\pm \mathrm{SD}$ (standard deviation).

${ }^{b}$ Concentration determined by MCR-ALS method.

${ }^{c}$ Concentration determined by univariate method.

One of the major challenges for lycopene quantification using a DAD detector was its low concentration in palm oil. This bioactive compound was not detected under some operating conditions during method development due to co-elution with matrix constituents, whereas the low purity of the pharmaceutical secondary standard (7.2\%) hampered its use to properly localize the lycopene peak. Due to this limitation, calibration was performed with the standard compound, but its concentration was 


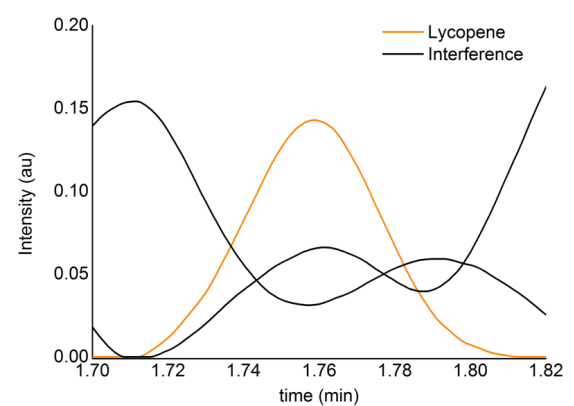

(a)

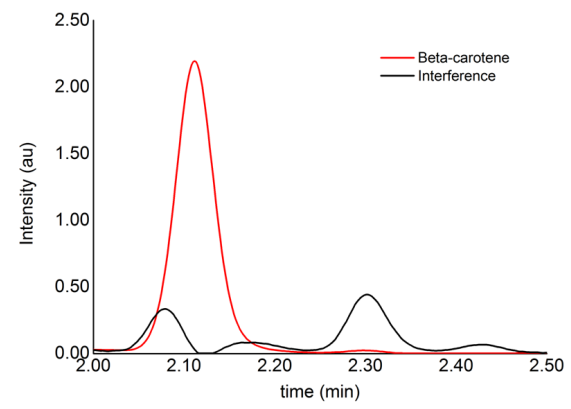

(c)

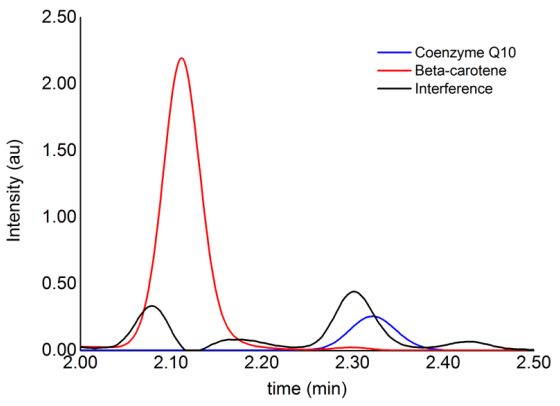

(e)

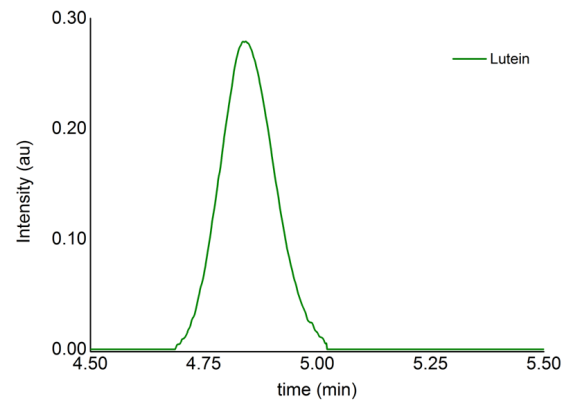

(g)
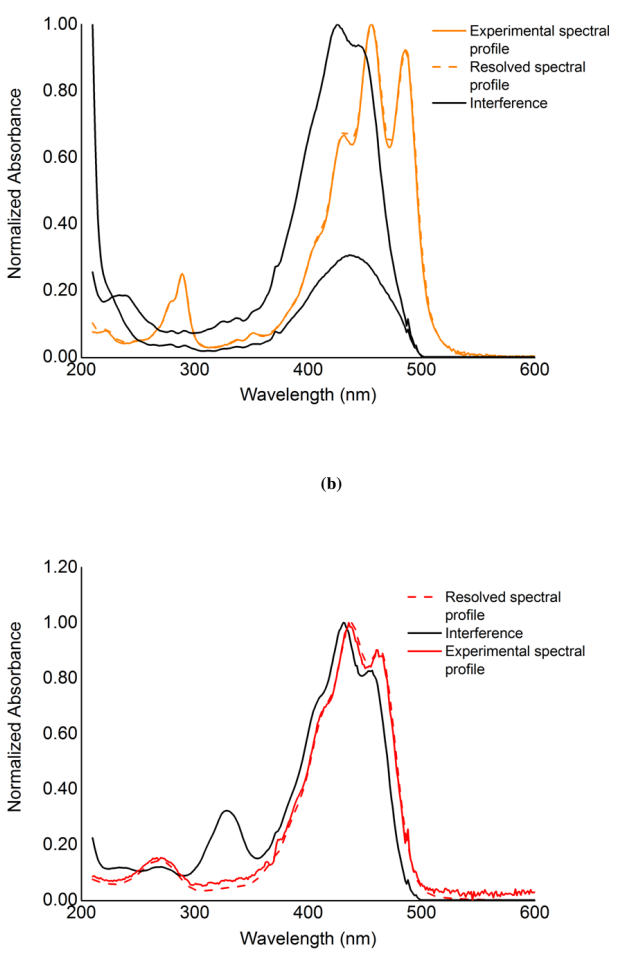

(d)
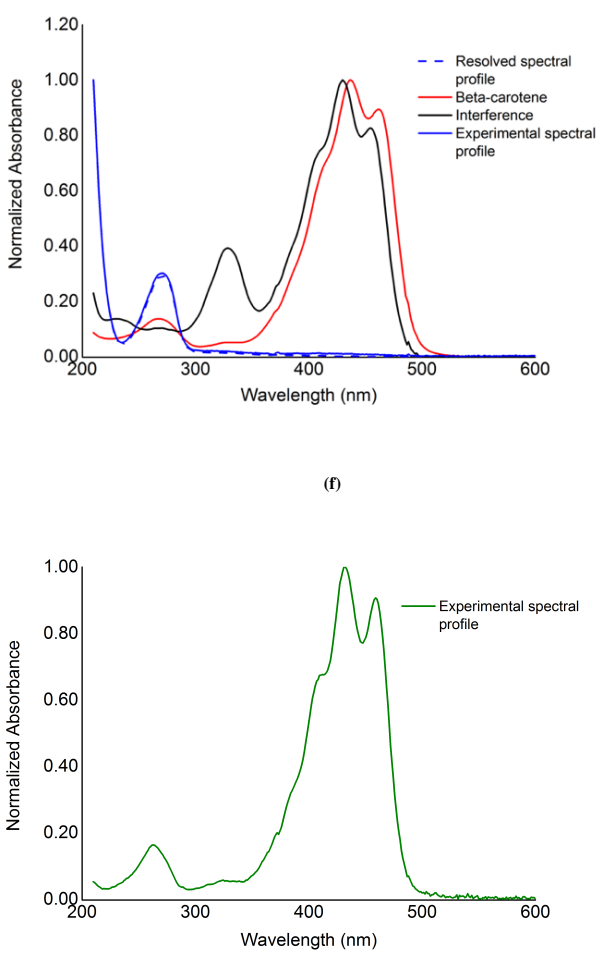

(h)

FIGURE 5 MCR-ALS recovery of chromatographic and spectral profiles of palm oil spiked with (a/b) lycopene, (c/d) betacarotene, (e/f) coenzyme Q10 and (g/h) lutein. Experimental spectral profiles were plotted for comparison (solid line). 


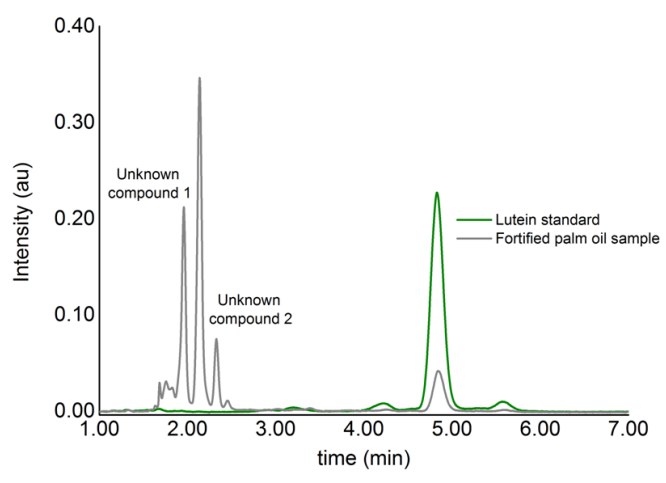

(a)

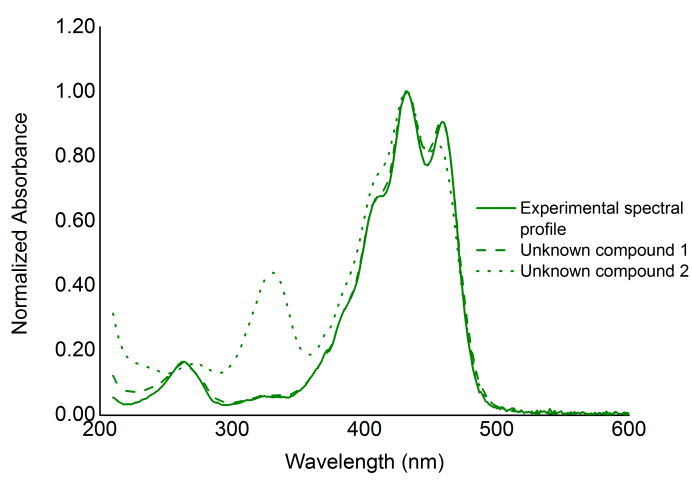

(b)

FIGURE 6 (a) Chromatograms of lutein standard compound (green) and spiked palm oil sample with lutein (grey); (b) Comparison of spectral profiles of unknown compounds and lutein standard compound.

lower than the limit of quantification, LOQ, $\left(3.12 \mu \mathrm{g} / \mathrm{mL}, 3.12 \times 10^{-3} \mathrm{~kg} / \mathrm{m}^{3}\right)$. Beta-carotene content was determined as being $183.48 \pm 1.66 \mu \mathrm{g} / \mathrm{mL}\left(183.48 \pm 1.66 \times 10^{-3} \mathrm{~kg} / \mathrm{m}^{3}\right)$. Coenzyme Q10 concentration was lower than the limit of detection, LOD, $\left(4.22 \mu \mathrm{g} / \mathrm{mL}, 4.22 \times 10^{-3} \mathrm{~kg} / \mathrm{m}^{3}\right)$. Lutein content was lower than the LOQ $\left(9.24 \mu \mathrm{g} / \mathrm{mL}, 9.24 \times 10^{-3} \mathrm{~kg} / \mathrm{m}^{3}\right)$. As previously discussed, it was postulated that other isomers of lutein might be present in the sample as a comparison of the spectra of unknown compounds with the lutein spectrum showed great similarity in their fine structure. Lutein quantification performed by the univariate approach accounted only for the amount of lutein standard added to palm oil samples.

The results showed that the UHPSFC technique coupled with chemometrics was a feasible tool to identify minor constituents of palm oil. The MCR-ALS method enabled to retrieve the carotenoid profiles whose compounds have similar UV-Visible absorption spectra. The use of this chemometric method was advantageous because the same UHPSFC data could be used for both univariate and multivariate calibration. Furthermore, the UHPSFC separation method developed allowed carotenoid and coenzyme Q10 separation to be done in less than 7 minutes with low consumption of organic solvents in contrast to the HPLC methods which require longer analysis times and greater amounts of organic solvents (Table 4). Gradient elution was not considered in this study because further studies will be performed to scale-up the analytical method to preparative scale. It is important to highlight that the difference between the carotenoid content obtained by this study and those reported in the literature (Table 4) may be attributed either to the wide variation of carotenoid content in palm oil which depends on the species and the region of production, and to the difficulties to quantify carotenoids and their isomers. ${ }^{[73.75]}$ These bioactive compounds are sensitive to light, heat, acid, and oxygen exposure, and their susceptibility to oxidation has to be considered during method development. ${ }^{[76]}$ Moreover, the high variability in carotenoid chemical structures and the limited availability of standard compounds increases the difficulty of carotenoid identification and quantification. 


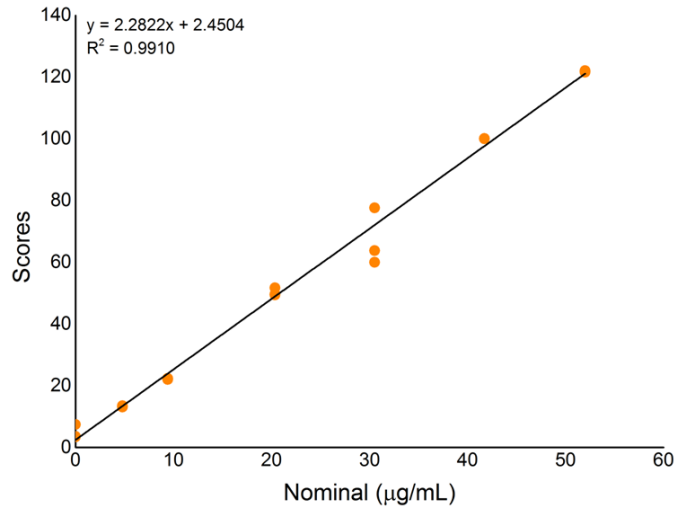

(a)

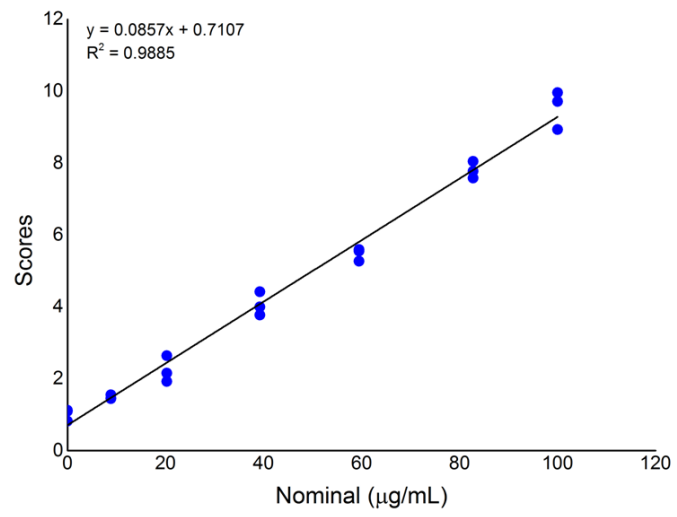

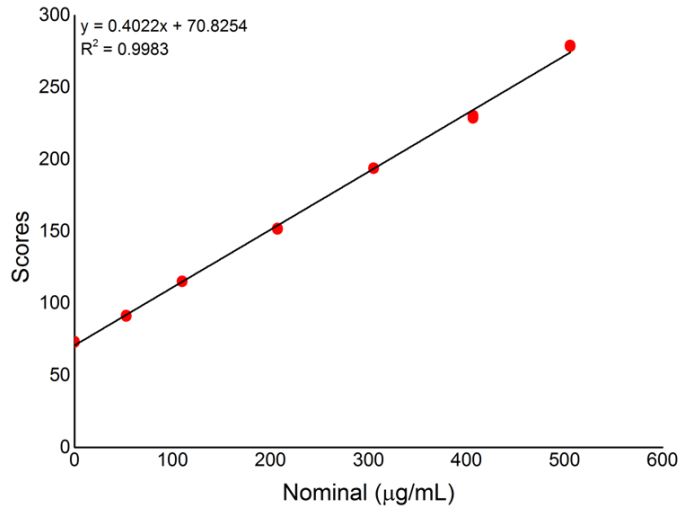

(b)

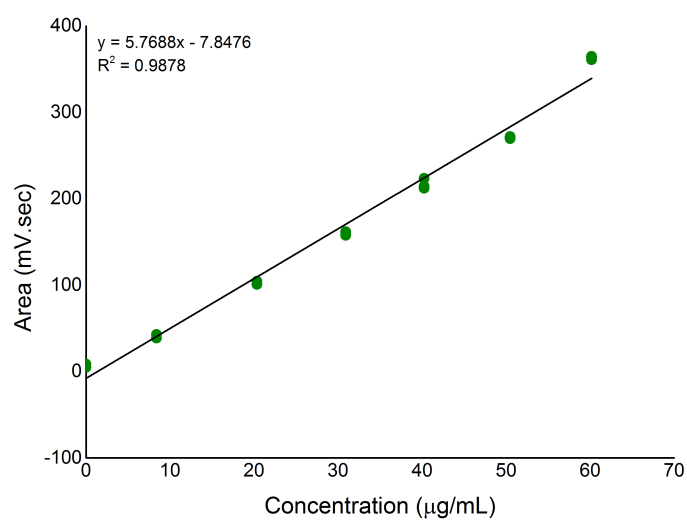

(d)

FIGURE 7 Second-order standard addition curves obtained by MCR-ALS scores vs nominal concentration of each compound: (a) lycopene, (b) beta-carotene, and (c) coenzyme Q10; (d) lutein calibration curve obtained by plotting peak areas vs concentrations of added standard.

\section{4 | CONCLUSIONS}

In this study, an analytical method for identification and quantification of lycopene, beta-carotene, coenzyme Q10, and lutein in palm oil was developed using UHPSFC. During method development, co-elution of some matrix components and the analytes was observed. Furthermore, low $\mathrm{S} / \mathrm{N}$ ratios and retention time shifts of the analytes in palm oil in relation to their standards were also observed which made it difficult to identify and quantify the target compounds using a DAD detector. Clean-up procedures employing solid-phase extraction cartridges, dispersive solid-phase extraction sorbents, Amberlite XAD7HP resin, and saponification were evaluated as means to physically reduce interferences. However, this approach did not remove interferences from matrix constituents and so the separation method was developed without a clean-up step.

Quantification of carotenoids and coenzyme Q10 were carried out under the optimized chromatographic conditions: Viridis $\mathrm{HSS} \mathrm{C}_{18} \mathrm{SB} 3.0$ x $150 \mathrm{~mm}$ column with particle size of $3.5 \mu \mathrm{m}, \mathrm{CO}_{2}: \mathrm{EtOH}(82: 18, \mathrm{v} / \mathrm{v})$, pressure $1600 \mathrm{psi}(11 \mathrm{MPa})$, column 
temperature $40^{\circ} \mathrm{C}(313 \mathrm{~K})$, sample manager temperature $17^{\circ} \mathrm{C}(290 \mathrm{~K})$, equilibration time between injections 4 minutes $(240 \mathrm{~s})$, flow rate $1.5 \mathrm{~mL} / \mathrm{min}\left(2.5 \times 10^{-8} \mathrm{~m}^{3} / \mathrm{s}\right)$, and injection volume $2 \mu \mathrm{L}\left(2 \times 10^{-9} \mathrm{~m}^{3}\right)$. Data analysis was performed by MCR-ALS and the results clearly showed good correlation between the experimental profiles and those recovered by MCR-ALS. Beta-carotene concentration in palm oil was $183.48 \pm 1.66 \mu \mathrm{g} / \mathrm{mL}\left(183.48 \pm 1.66 \times 10^{-3} \mathrm{~kg} / \mathrm{m}^{3}\right)$. Lycopene concentration was lower than the LOQ $\left(3.12 \mu \mathrm{g} / \mathrm{mL}, 3.12 \times 10^{-3} \mathrm{~kg} / \mathrm{m}^{3}\right)$. Coenzyme Q10 concentration was lower than the LOD $\left(4.22 \mu \mathrm{g} / \mathrm{mL}, 4.22 \times 10^{-3} \mathrm{~kg} / \mathrm{m}^{3}\right)$ and lutein concentration determined by the univariate method was lower than the LOQ $\left(9.24 \mu \mathrm{g} / \mathrm{mL}, 9.24 \times 10^{-3} \mathrm{~kg} / \mathrm{m}^{3}\right)$. The results showed that quantification of lycopene, coenzyme Q10, and lutein requires a more sensitive detection method due to the low concentration of these bioactive compounds in palm oil. 
TABLE 4 Carotenoids and coenzyme Q10 content in palm oil reported in the literature

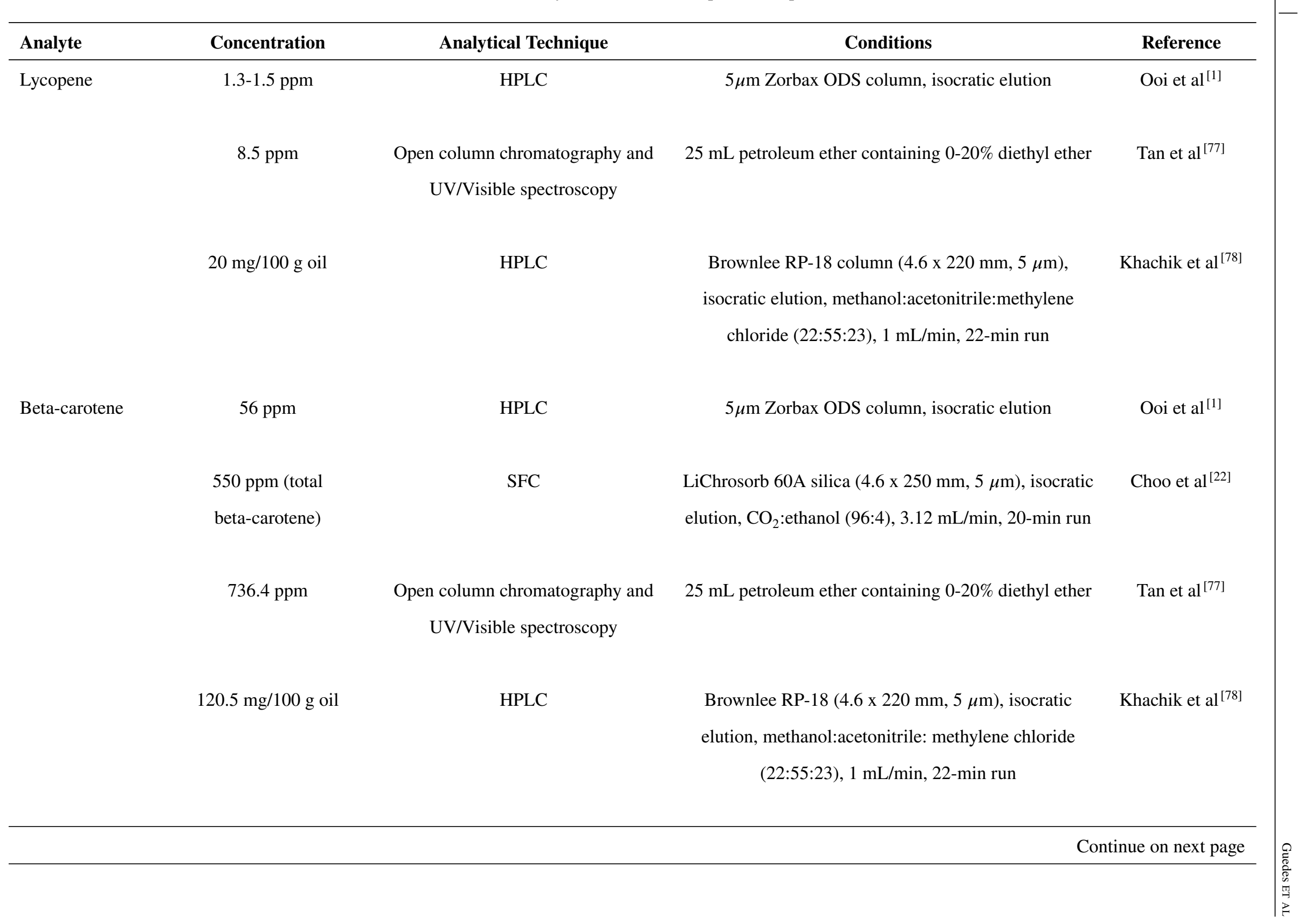




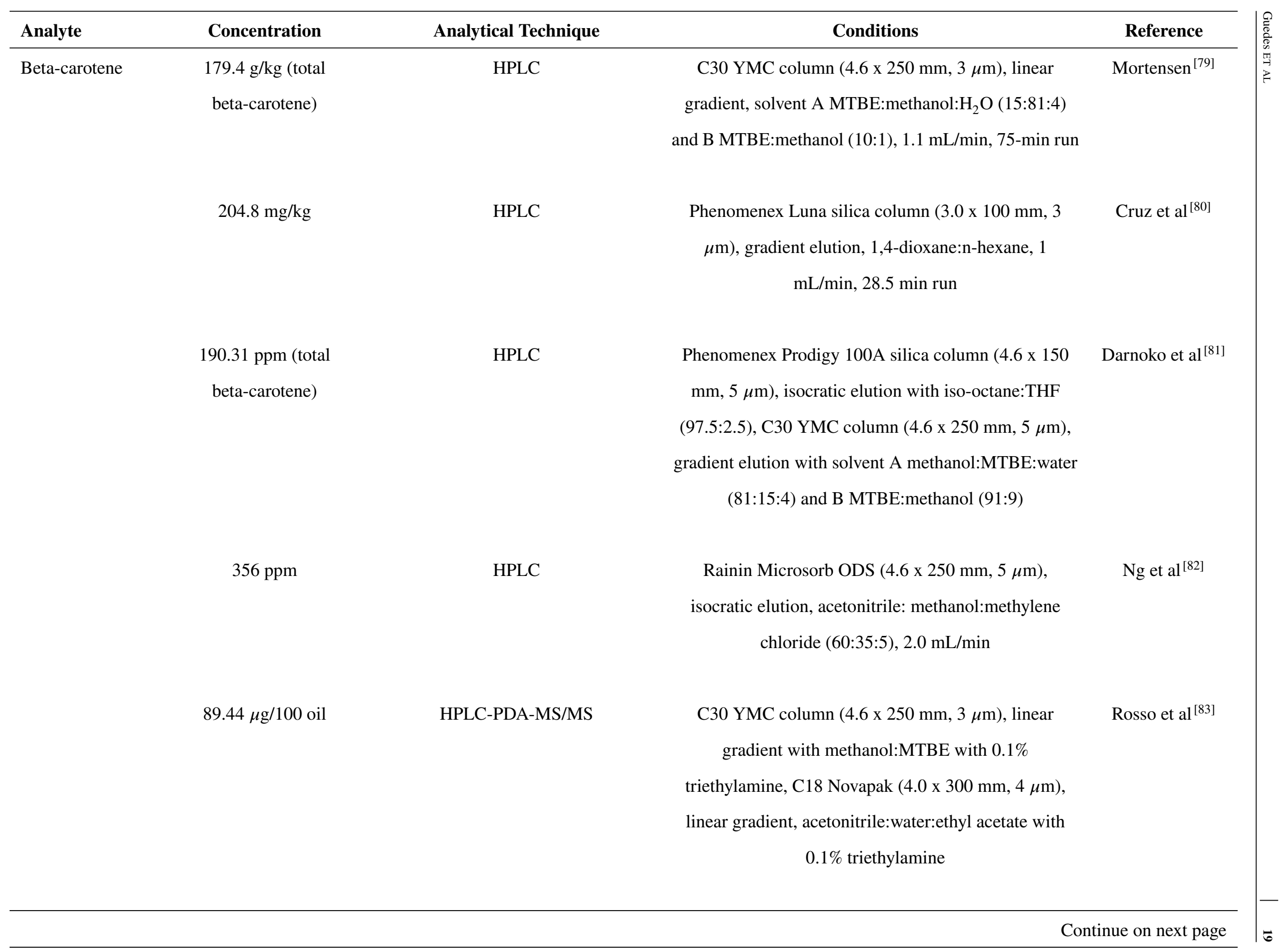




\begin{tabular}{|c|c|c|c|c|}
\hline Analyte & Concentration & Analytical Technique & Conditions & Reference \\
\hline Coenzyme Q10 & $10-80 \mathrm{ppm}$ & $\mathrm{SFC}$ & Metaphase RPC18 (4.6 x $250 \mathrm{~mm}), \mathrm{CO}_{2}$ :methanol & $\mathrm{Ng}$ et al ${ }^{23]}$ \\
\hline \multirow[t]{4}{*}{ Lutein } & $1.8 \mathrm{mg} / \mathrm{kg}$ & HPLC & $\begin{array}{l}\text { Phenomenex Luna silica column }(3.0 \times 100 \mathrm{~mm}, 3 \\
\mu \mathrm{m}) \text {, gradient elution, 1,4-dioxane:n-hexane, } 1 \\
\mathrm{~mL} / \mathrm{min}, 28.5 \text { min run }\end{array}$ & Cruz et al ${ }^{80]}$ \\
\hline & $11.85 \mathrm{ppm}$ & HPLC & $\begin{array}{l}\text { Phenomenex Prodigy 100A silica column (4.6 x } 150 \\
\text { mm, } 5 \mu \mathrm{m} \text { ), isocratic elution with iso-octane:THF } \\
\text { (97.5:2.5), C30 YMC column ( } 4.6 \text { x } 250 \mathrm{~mm}, 5 \mu \mathrm{m} \text { ), } \\
\text { gradient elution with solvent A methanol:MTBE:water } \\
\qquad \text { (81:15:4) and B MTBE:methanol (91:9) }\end{array}$ & Darnoko et al 811 \\
\hline & $0.11 \mu \mathrm{g} / 100$ oil & HPLC-PDA-MS/MS & $\begin{array}{l}\text { C30 YMC column }(4.6 \text { x } 250 \mathrm{~mm}, 3 \mu \mathrm{m}) \text {, linear } \\
\text { gradient with methanol:MTBE with } 0.1 \% \\
\text { triethylamine, C18 Novapak ( } 4.0 \times 300 \mathrm{~mm}, 4 \mu \mathrm{m}) \text {, } \\
\text { linear gradient, acetonitrile:water:ethyl acetate with } \\
\quad 0.1 \% \text { triethylamine }\end{array}$ & Rosso et al \\
\hline & $11.55 \mu \mathrm{g} / 100 \mathrm{~g}$ oil & HPLC & $\begin{array}{l}\text { SGE C18 column }(4.6 \times 250 \mathrm{~mm}, 5 \mu \mathrm{m}) \text {, } \\
\text { acetonitrile:dichloromethane:methanol }(6: 2: 2) \text { with } \\
0.1 \% \text { ammonium acetate, } 1 \mathrm{~mL} / \mathrm{min}\end{array}$ & Aruna et al \\
\hline
\end{tabular}




\section{ACKNOWLEDGMENTS}

The authors acknowledge São Paulo Research Foundation (FAPESP), Instituto Nacional de Ciência e Tecnologia de Bioanalítica (INCTBio) and the Brazilian National Council for Scientific and Technological Development (CNPq) for the financial support and scholarship. The authors would also like to thank Kelvis Vieira Campos, Larissa Ferreira Torres and Ronney José Oliveira Santos from Universidade Tiradentes for their excellent technical assistance with palm oil extraction and Waters Technologies for the column used in the study.

\section{SUPPORTING INFORMATION}

Figure 1. Chromatograms of the clean-up procedures: (1) lycopene; (2) beta-carotene, and (3) lutein. Chromatographic conditions: Acquity UPC ${ }^{2} \mathrm{HSS} \mathrm{C}_{18} \mathrm{SB} 3.0$ x $150 \mathrm{~mm}, 1.8 \mu \mathrm{m}$ column, mobile phase $\mathrm{CO}_{2}: \mathrm{EtOH}(84.5: 15.5$, v/v), pressure 1500 psi (10 MPa), column temperature $40^{\circ} \mathrm{C}(313 \mathrm{~K})$, sample temperature $5^{\circ} \mathrm{C}(278 \mathrm{~K})$, flow rate $1.5 \mathrm{~mL} / \mathrm{min}\left(2.5 \times 10^{-8} \mathrm{~m}^{3} / \mathrm{s}\right)$, and injection volume $2 \mu \mathrm{L}\left(2 \times 10^{-9} \mathrm{~m}^{3}\right)$.

\section{References}

1. Ooi CK, Choo YM, Yap SC, Basiron Y, Ong ASH. Recovery of carotenoids from palm oil. J Am Oil Chem Soc. 1994;71:423426.

2. Mba OI, Dumont MJ, Ngadi M. Palm oil: processing, characterization and utilization in the food industry - A review. Food Biosci. 2015;10:26-41.

3. Ng M, Choo Y. Packed supercritical fluid chromatography for the analyses and preparative separations of palm oil minor components. Am J Analyt Chem. 2015;6:645-650.

4. Akanda MJH, Sarker MZI, Ferdosh S, Manap MYA, Ab Rahman NNN, Ab Kadir MO. Applications of supercritical fluid extraction (SFE) of palm oil and oil from natural sources. Molecules. 2012;17:1764-1794.

5. Cornelius JA. Palm oil and palm kernel oil. Progress in the Chemistry of Fats and other Lipids. 1977;15:5-27.

6. Karppi J, Nurmi T, Olmedilla-Alonso B, Granado-Lorencio F, Nyyssö-nen K. Simultaneous measurement of retinol, $\alpha$ tocopherol and six carotenoids in human plasma by using an isocratic reversed-phase HPLC method. $J$ Chromatogr B. 2008;867:226-232.

7. Kirti K, Amita S, Priti S, Kumar AM, Jyoti S. Colorful world of microbes: carotenoids and their applications. Advances in Biology. 2014;2014:1-13.

8. Rodriguez-Concepcion M, Avalos J, Bonet ML, et al. A global perspective on carotenoids: metabolism, biotechnology, and benefits for nutrition and health. Prog Lipid Res. 2018;70:62-93. 
9. Eggersdorfer M, Wyss A. Carotenoids in human nutrition and health. Arch Biochem Biophys. 2018;652:18-26.

10. Amorim-Carrilho KT, Cepeda A, Fente C, Regal P. Review of methods for analysis of carotenoids. TRAC-Trend Anal Chem. 2014;56:49-73.

11. Rivera SM, Christou P, Canela-Garayoa R. Identification of carotenoids using mass spectrometry. Mass Spectrom Rev. 2014;33:353-372.

12. Jumaah F, Plaza M, Abrahamsson V, Turner C, Sandahl M. A fast and sensitive method for the separation of carotenoids using ultra-high performance supercritical fluid chromatography-mass spectrometry. Anal Bioanal Chem. 2016;408:58835894.

13. Bank G, Kagan D, Madhavi D. Coenzyme Q10: clinical update and bioavailability. Evid Based Complement Alternat Med. 2011;16:129-137.

14. López-Lluch G, Pozo-Cruz J, Sánchez-Cuesta A, Belén Cortés-Rodríguez A, Navas P. Bioavailability of coenzyme Q10 supplements depends on carrier lipids and solubilization. Nutrition. 2019;57:133-140.

15. Ortiz-Estrada CH, Díaz-Díaz CY, Cruz-Olivares J, Pérez-Alonso C. Coenzyme Q10 microparticles formation with supercritical carbon dioxide. Rev Mex Ing Quim. 2015;14:49-59.

16. Carotenoids market size, share \& trends analysis report by source (natural, synthetic), by product (beta-carotene, lutein, lycopene, astaxanthin, zeaxanthin, canthaxanthin), by application, and segment forecasts, 2018-2025. Report ID: GVR-168038-321-8, Grand View Research, Inc.; 2016.

17. Coenzyme $\mathrm{Q} 10$ market size, share \& trend analysis report by application (dietary supplements, pharmaceuticals, cosmetics) by region and segment forecasts, 2014-2024. Report ID: 978-1-68038-245-7, Grand View Research, Inc.; 2014.

18. Bernal JL, Martín MT, Toribio L. Supercritical fluid chromatography in food analysis. J Chromatogr A. 2013;1313:24-36.

19. Li B, Zhao H, Liu J, et al. Application of ultra-high performance supercritical fluid chromatography for the determination of carotenoids in dietary supplements. J Chromatogr A. 2015;1425:287-292.

20. Nováková L, Grand-Guillaume Perrenoud A, Francois I, West C, Lesellier E, Guillarme D. Modern analytical supercritical fluid chromatography using columns packed with sub-2 $\mu$ m particles: A tutorial. Anal Chim Acta. 2014;824:18-35.

21. Lesellier E, West C. The many faces of packed column supercritical fluid chromatography - A critical review. J Chromatogr A. $2015 ; 1382: 2-46$.

22. Choo YM, Ng MH, Ma AN, Chuah CH, Hashim MA. Application of supercritical fluid chromatography in the quantitative analysis of minor components (carotenes, vitamin E, sterols, and squalene) from palm oil. Lipids. 2005;40:429-432. 
23. Ng MH, Choo YM, Ma AN, Chuah CH, Hashim MA. Separation of coenzyme Q10 in palm oil by supercritical fluid chromatography. Am J Appl Sci. 2006;3:1929-1932.

24. Desfontaine V, Tarafder A, Hill J, et al. A systematic investigation of sample diluents in modern supercritical fluid chromatography. J Chromatogr A. 2017;1511:122-131.

25. Lemasson E, Bertin S, Hennig P, Lesellier E, West C. Comparison of ultra-high performance methods in liquid and supercritical fluid chromatography coupled to electrospray ionization - mass spectrometry for impurity profiling of drug candidates. J Chromatogr A. 2016;1472:117-128.

26. Waters Corporation. Acquity UPC ${ }^{2}$ system instrument specifications. Manual 720004226EN; 2013.

27. Jesus AA, Almeida LC, Silva EA, et al. Extraction of palm oil using propane, ethanol and its mixtures as compressed solvent. J Supercrit Fluid. 2013;81:245-253.

28. Guedes LS, Jardim ICSF, Melo LV, Beppu MM, Breitkreitz MC, Santana CC. Study of the effect of the operating parameters on the separation of bioactive compounds of palm oil by ultra-high performance supercritical fluid chromatography using a design of experiments approach. Can J Chem Eng. 2017;95:2306-2314.

29. Rajendran A. Design of preparative-supercritical fluid chromatography. J Chromatogr A. 2012;1250:227-249.

30. Dejaegher B, Heyden YV. Experimental designs and their recent advances in set-up, data interpretation, and analytical applications. J Pharmaceut Biomed. 2011;56:141-158.

31. Baş Deniz, H. Boyac1 . Modeling and optimization I: Usability of response surface methodology. J Food Eng. 2007;78:836 $-845$.

32. Gharibzahedi SMT, Mousavi SM, Hamedi M, Khodaiyan F. Application of response surface modeling to optimize critical structural components of walnut-beverage emulsion with respect to analysis of the physicochemical aspects. Food Bioprocess Tech. 2013;6:456-469.

33. Huang W, Li Z, Niu H, Li D, Zhang J. Optimization of operating parameters for supercritical carbon dioxide extraction of lycopene by response surface methodology. J Food Eng. 2008;89:298-302.

34. Bortolato SA, Arancibia JA, Escandar GM, Olivieri AC. Time-alignment of bidimensional chromatograms in the presence of uncalibrated interferences using parallel factor analysis: Application to multi-component determinations using liquidchromatography with spectrofluorimetric detection. Chemometr Intell Lab. 2010;101:30-37.

35. Wang JY, Wu HL, Sun YM, et al. Simultaneous determination of phenolic antioxidants in edible vegetable oils by HPLC-FLD assisted with second-order calibration based on ATLD algorithm. J Chromatogr B. 2014;947-948:32-40.

36. Vosough M, Salemi Amir. Second-order standard addition for deconvolution and quantification of fatty acids of fish oil using GC-MS. Talanta. 2007;73:30-36. 
37. Sanchez E, Kowalski BR. Tensorial resolution: A direct trilinear decomposition. J Chemom. 1990;4:29-45.

38. El-Sheikh AH, Al-Degs YS. Spectrophotometric determination of food dyes in soft drinks by second order multivariate calibration of the absorbance spectra-pH data matrices. Dyes Pigments. 2013;97:330-339.

39. Arancibia JA, Damiani PC, Escandar GM, Ibañez GA, Olivieri AC. A review on second- and third-order multivariate calibration applied to chromatographic data. J Chromatogr B. 2012;910:22-30.

40. Escandar GM, Goicoechea HC, Peña Arsenio, Olivieri AC. Second- and higher-order data generation and calibration: A tutorial. Anal Chim Acta. 2014;806:8-26.

41. Jiménez-Carvelo AM, Cruz CM, Olivieri AC, González-Casado A, Cuadros-Rodríguez L. Classification of olive oils according to their cultivars based on second-order data using LC-DAD. Talanta. 2019;195:69-76.

42. Bortolato SA, Olivieri AC. Chemometric processing of second-order liquid chromatographic data with UV-vis and fluorescence detection. A comparison of multivariate curve resolution and parallel factor analysis 2. Anal Chim Acta. 2014;842:11-19.

43. Wold S, Geladi P, Esbensen K, Öhman J. Multi-way principal components-and PLS-analysis. J Chemom. 1987;1:41-56.

44. Bro R. Multiway calibration. Multilinear PLS. J Chemom. 1996;10:47-61.

45. Jaumot J, Juan A, Tauler R. MCR-ALS GUI 2.0: New features and applications. Chemometr Intell Lab. 2015;140:1-12.

46. Ruckebusch C, Blanchet L. Multivariate curve resolution: A review of advanced and tailored applications and challenges. Anal Chim Acta. 2013;765:28-36.

47. Jaumot J, Gargallo R, Juan A, Tauler R. A graphical user-friendly interface for MCR-ALS: A new tool for multivariate curve resolution in MATLAB. Chemometr Intell Lab. 2005;76:101-110.

48. Tauler R. Multivariate curve resolution applied to second order data. Chemometr Intell Lab. 1995;30:133-146.

49. Escandar GM, Olivieri AC. Multi-way chromatographic calibration-A review. J Chromatogr A. 2019;1587:2-13.

50. Navarro-Reig M, Jaumot J, Beek TA, Vivó-Truyols G, Tauler R. Chemometric analysis of comprehensive LC $\times$ LC-MS data: Resolution of triacylglycerol structural isomers in corn oil. Talanta. 2016;160:624-635.

51. Anzardi MB, Arancibia JA, Olivieri AC. Interpretation of matrix chromatographic-spectral data modeling with parallel factor analysis 2 and multivariate curve resolution. J Chromatogr A. 2019;1604:460502.

52. Olivieri AC, Wu HL, Yu RQ. MVC2: A MATLAB graphical interface toolbox for second-order multivariate calibration. Chemometr Intell Lab. 2009;96:246-251.

53. Zhang X, Zhang Z, Tauler R. Evaluation of the extension of rotation ambiguity associated to multivariate curve resolution solutions by the application of the MCR-BANDS method. Talanta. 2019;202:554-564. 
54. Sousa ES, Pinto L, Araujo MCU. A chemometric cleanup using multivariate curve resolution in liquid chromatography: Quantification of pesticide residues in vegetables. Microchem J. 2017;134:131-139.

55. Sousa ES, Schneider MP, Pinto L, Araujo MCU, Gomes AA. Chromatographic quantification of seven pesticide residues in vegetable: Univariate and multiway calibration comparison. Microchem J. 2020;152:104301.

56. Rivera S, Canela R. Influence of sample processing on the analysis of carotenoids in maize. Molecules. 2012;17:1125511268.

57. Rodriguez-Amaya DB. A guide to carotenoid analysis in food. Washington, D.C. OMNI Research; 2001.

58. Britton G, Liaaen-Jensen S, Pfander H. Carotenoid: Handbook. Basle, Birkhauser Verlag; 2004.

59. Giuffrida D, Donato P, Dugo P, Mondello L. Recent analytical techniques advances in the carotenoids and their derivatives determination in various matrixes. J Agric Food Chem. 2018;66:3302-3307.

60. Giuffrida D, Zoccali M, Mondello L. Carotenoid and Apocarotenoid Analysis by SFE-SFC-QqQ/MS. In: RodríguezConcepción M, Welsch R, eds. Plant and Food Carotenoids. Methods in Molecular Biology, New York: Humana 2020 (pp. 209-219).

61. Ribeiro JAA, Almeida ES, Neto BAD, Abdelnur PV, Monteiro S. Identification of carotenoid isomers in crude and bleached palm oils by mass spectrometry. LWT. 2018;89:631-637.

62. Arathi BP, Sowmya PRR, Vijay K, et al. An improved method of UPLC-PDA-MS/MS analysis of lycopene isomers. Food Anal Methods. 2015;8:1962-1969.

63. Dachtler M, Glaser T, Kohler K, Albert K. Combined HPLC-MS and HPLC-NMR on-line coupling for the separation and determination of lutein and zeaxanthin stereoisomers in spinach and in retina. Anal Chem. 2001;73:667-674.

64. Bernal J, Mendiola JA, Ibáñez E, Cifuentes A. Advanced analysis of nutraceuticals. J Pharmaceut Biomed. 2011;55:758774.

65. Iftikhar, Tan H, Zhao Y. Enrichment of $\beta$-carotene from palm oil using supercritical carbon dioxide pretreatment-solvent extraction technique. LWT-Food Sci Technol. 2017;83:262-266.

66. Iftikhar, Tan $\mathrm{H}$, Zhao Y. Enriching $\beta$-carotene from fatty acid esters mixture of palm oil using supercritical $\mathrm{CO}_{2}$ in the silica-packed column. J CO2 Util. 2018;26:93-97.

67. Moh MH, Che Man YB, Badlishah BS, Jinap S, Saad MS, Abdullah WJW. Quantitative analysis of palm carotene using Fourier transform infrared and near infrared spectroscopy. J Am Oil Chem’ Soc. 1999;76:249-254.

68. Batistella CB, Wolf Maciel MR. Recovery of carotenoids from palm oil by molecular distillation. Comput Chem Eng. 1998;22:S53-S60. 
69. Batistella CB, Moraes EB, Maciel Filho R, Wolf Maciel MR. Molecular distillation process for recovering biodiesel and carotenoids from palm oil. Appl Biochem Biotech. 2002;98:1149-1159.

70. Chuang MH, Brunner G. Concentration of minor components in crude palm oil. J Supercrit Fluid. 2006;37:151-156.

71. Damayant S, Andry S, Khairurrijal , Kartasasmita RE. Isolation of beta-carotene from palm (Elaeis guineensis Jacq.) oil using transesterification-adsorption-desorption method and its characterization. J Applied Sci. 2014;14:2615-2621.

72. Han NM, Choo YM. Isolation and recovery of phytonutrients in palm by isocrated and isobaric flash chromatography. J Oil Palm Res. 2013;25:165-169.

73. Choo YM. Palm Oil Carotenoids. Food Nutr Bull. 1994;15:1-8.

74. Corley R, Tinker P. The products of the oil palm and their extraction. In: Corley R, Tinker P, eds. The oil palm, Danvers: John Wiley \& Sons, Ltd 2015 (pp. 460-482).

75. Fernandez Rojas XE, Shier NW, Watkins BA. Effect of alkali saponification, enzymatic hydrolysis and storage time on the total carotenoid concentration of Costa Rican crude palm oil. J Food Compost Anal. 2000;13:179-187.

76. Wrolstad RE, Acree TE, Decker EA, et al. Carotenoids. In: Wrolstad RE, Acree TE, Decker EA, et al. , eds. Handbook of Food Analytical Chemistry, John Wiley \& Sons, Ltd 2005 (pp. 71-119).

77. Tan B, Grady CM, Gawienowski AM. Hydrocarbon carotenoid profiles of palm oil processed fractions. J Am Oil Chem' Soc. 1986;63:1175-1179.

78. Khachik F, Beecher GR. Application of a C-45-beta-carotene as an internal standard for the quantification of carotenoids in yellow/orange vegetables by liquid chromatography. J Agr Food Chem. 1987;35:732-738.

79. Mortensen A. Analysis of a complex mixture of carotenes from oil palm (Elaeis guineensis) fruit extract. Food Res Int. 2005;38:847-853.

80. Cruz R, Casal S. Direct analysis of vitamin A, vitamin E, carotenoids, chlorophylls and free sterols in animal and vegetable fats in a single normal-phase liquid chromatographic run. J Chromatogr A. 2018;1565:81-88.

81. Darnoko D, Cheryan M, Moros E, Jerrel J, Perkins EG. Simultaneous HPLC analysis of palm carotenoids and tocopherols using a C-30 column and photodiode array detector. J Liq Chromatogr R T. 2000;23:1873-1885.

82. Ng JH, Tan B. Analysis of palm oil carotenoids by HPLC with diode-array detection. J Chromatogr Sci. 1988;26:463-469.

83. Rosso VV, Mercadante AZ. Identification and quantification of carotenoids, by HPLC-PDA-MS/MS, from Amazonian fruits. J Agr Food Chem. 2007;55:5062-5072.

84. Aruna G, Mamatha BS, Baskaran V. Lutein content of selected Indian vegetables and vegetable oils determined by HPLC. J Food Compos Anal. 2009;22:632-636. 
$\square$ 